


\title{
Searching for effectiveness in ELT: towards the construction of a framework for continuous improvement in state funded secondary language class in Spain in the light of recent legislative changes
}

\author{
STEPhen P. Hughes \\ Colegio “Juan XXIII”, (Zaidín) Granada
}

\begin{abstract}
Drawing on a working experience of language teaching, teacher training and the implementation of the EFQM model of excellence, and taking into account the recent legislative changes in the Spanish state educational system ${ }^{1}$, this paper studies a number of current trends relating to quality and effectiveness in education with a view to examining possible applications for improving language teaching and learning. Apart from its intended informative purpose, this study proposes the development of a framework similar to those already established within education but not as yet fully applied to formal language instruction in Spain, with the intention of finding ways to improve a number of key areas in the management of second language teaching and learning through the systematic implementation of effectiveness activities.
\end{abstract}

KEY WORDS: Quality, ELT, Effectiveness.

\section{INTRODUCTION}

'Quality' and 'effectiveness' have been buzz-words in general education for a number of years, and with forty-one mentions of the former and thirteen variants of the latter in this thirty page document, the new educational legislation in formal Spanish education has not understated their importance. Quality assurance and, consequently, teacher autonomy are two factors this law appears to engage and the question posed here is to what extent the different bodies (inspectors, teacher advisors, teacher trainers, etc.) can have a positive impact on the daily dynamics of instruction and annual results in the national education system without jeopardising teacher motivation.

This law, commonly known as La Ley de Calidad (B.O.E. No 307: 45188-45220), is by definition aimed at improving quality in education, yet it has brought with it a number of controversies manifested in both strike action and local government opposition. With the

${ }^{1}$ Ley Orgánica 10/2002, de 23 de diciembre, de Calidad de la Educación, citations of which are taken in this paper from its original ministerial context of the 'Boletín Oficial del Estado' or BOE $N^{\circ} 307$ (LOCE). 
advent of these recent changes in the Spanish educational system it would seem at first glance that, as teachers, many of us have willingly or unwillingly taken a step towards becoming part of a culture which belongs more to the area of commercial management than that of formal classroom instruction. Indeed, the very mention of the word 'Quality' may seem more reminiscent of quality control over soulless consumer goods rather than an instrument, framework or, indeed, philosophy which can be directly applied to enhance the more humanistic areas of teaching and learning.

Among the reasons openly stated for the adoption of this new law are a number of 'important deficiencies' (B.O.E. No 307: 45189) which have arisen from the failure of previous laws to ensure standards and to prevent drop-out levels. There have been a number of studies carried out by national and international bodies which do indeed reveal substantial deficiencies within the Spanish education system as a whole and in particular at secondary level. It is for this reason that the recent changes to the education system purport to promote a 'culture of effort' whereby academic standards are raised, initiatives are encouraged, and an orderly and affective yet demanding climate is created through 'the transmission of positive expectations' from teacher to learner (B.O.E. 307: 45189). The division between the ideal and the reality of previous educational measures can be seen to a certain extent in the fact that a quarter of secondary school leavers fail to reach basic academic standards (B.O.E. 307: 45189). In EFL terms, there has also been a gap between the communicative goals provided in legislation for secondary language teaching and the failure to employ nation-wide communicative-based assessment instruments in pre-university selection proceedings (Selectividad). In many ways, the teaching of languages in Spain may have followed Johnson's (1989: 6) observation that the concern of stakeholders (teachers, students, parents administrators and inspectors) may have given priority to results of examinations rather than of communicative competence. If the Administration intends to improve upon these results, therefore, among the many questions logically raised are who is to guarantee the improvement of standards and how is it to be done? It is with these questions and this problematic background that I wish to present the two objectives of this paper. The first of these is to highlight some of the more important aspects of 'effectiveness' or 'quality' models which appear to have provided the inspiration for recent legislative changes. The second objective of this study is to tentatively suggest an effectiveness framework in language instruction based on the principles of such models, which, while taking on board governmental calls for an improvement in quality and innovation, attempts to place the English language teachers at the centre of improvement and decisionmaking processes within their own specific contexts.

It must be said at this stage that the presentation of a suggested framework is by no means prescriptive. Indeed, it is argued that the implementation of such models are fraught with difficulties and, given the lack of empirical studies carried out on recognised frameworks of quality or excellence in education in general, any possible application would need to be tested in context not only for reliability and validity, but also for viability. This study, therefore, represents the starting point in a question which is of interest to this teacher and is intended to provide food for thought, acting perhaps as a point of reference and offered up for whatever criticism may seem appropriate. 


\section{WhO CAN BRING EFFECTIVENESS INTO THE LANGUAGE CLASS?}

\subsection{Curriculum writers?}

The gap between governmental objectives and the reality of classroom practice has already been mentioned in the introduction of this paper, indeed, the adoption of new legislation is partly justified by the failure of previous laws to reach their intended objectives. However, within the last two years teachers in Spain have been required to introduce new class materials which are compliant with the introduction of the new law. This has essentially meant that course books are to provide students with a greater level of English in order to comply with the curriculum and improve national standards. It is yet to be seen if this decision effectively represents a case of the educational board 'running before it walks' or, indeed, 'shooting itself in the foot', given that many, including Johnson (1989:10) in the case of modern language curriculum design, have seen overoptimistic objectives as 'a frequent cause of curricular failure'. In the end, as Tarone \& Yule (1989:36) indicate, the teacher may find a number of discrepancies between what is written in the curriculum and what individual learner needs the teacher confronts; and in the end, it will be the teacher who will have to deal with these discrepancies.

\subsection{Inspectors?}

Another group to be involved in assuring that the principles of new legislation are implemented is the inspectorate. However, González et al. (1995:112) in a nationwide governmental study found that only $26.7 \%$ of secondary school teachers agreed that inspectors should carry out external assessments on their teaching as opposed to $38 \%$ who were against this. This could question the degree to which this group would be favourably accepted as a credible means of implementing improvement processes and hence have a significant impact on the effectiveness of teaching and learning. Similarly, in the international field of ELT there have been various signs of a lack of faith in externally orientated evaluators as agents in change processes. Alderson \& Scott (1992:25) mention the reluctance of participants in a nation-wide ESP evaluation project in Brazil to have external assessment, while Thomas (2003: 238-239) questions the durability of improvements made in the face of an imminent evaluation carried out by accreditation and inspection organisations.

\subsection{Quality Assurance Agencies?}

Other groups, such as those using the European Foundation for Quality Management plan (EFQM), involved primarily in the private sector have also begun to participate in external assessment procedures in Spain. Within Europe, such models have had considerable influence in educational circles, not least of which in Great Britain, where Estelle Morris, at that time Secretary of State for Education, had indeed promoted the use of quality tools in schools in Lloyds TSB (2002 a: 5). Yet the development of quality programmes in education has not been without its own setbacks. Having spent four years co-ordinating the implementation of the EFQM model at a private school and having assisted and intervened during regional 
and national benchmarking sessions, this teacher would mention that one of a number of difficulties observed is in spreading the fundamental messages of quality from school management to staff in that some teachers consider the entire process to be an externally imposed instrument. A similar view is also expressed by Welsh \& Metcalf (2003: 36) who, in examining participation in quality programmes in higher education, state that:

There is a prevailing suspicion that institutional effectiveness has been forced on institutions by external entities ... If campus constituents, including faculty, believe that institutional effectiveness activities are undertaken primarily to satisfy the standards of external groups, they will likely assign lower levels of importance to them.

There is also the problem that those trained in quality management are primarily those involved in management and the organisational skills obtained by them more often than not reach individual teachers, if they reach them at all, in a watered down form with their own corporate or personal agendas. If we couple this with the fact that instructional effectiveness matters in general are often a top-down concern, imposed by management or the educational administration, it is quite easy to see how such measures could be paid only superficial lipservice or, indeed, rejected outright.

\subsection{Teacher trainers?}

Johnson (1989: 9) states that the teacher trainer 'forms the bridge between the syllabus committee and the classroom'. However, as far as in-service teacher training in Spain is concerned, Barquín \& Fernández (1998 p.636-638), provide a different set of conclusions with regard to the relationship that exists between teachers and official teaching support centres (commonly known as CEPs). Based on a survey of 1638 teachers, they present a number of insights as to how teachers view the usefulness of courses organised by such centres, including the fact that the prime reason for attending courses was not to learn how to improve their teaching but to obtain credit. Similar findings led González et al. (1995: 107108) to conclude that there was a low degree of confidence placed by teachers on the efficiency of such centres. The data provided from their research calls into question the appropriateness of this type of course for teachers especially if we add to this the criticisms provided by Lamb (1995: 72-73), who, in his own context, casts doubts on the effectiveness of short inset courses as a way to improve teaching and learning in the field of ELT. Lamb (ibid: 79) suggests that while such courses may be exciting and motivating, very often there are relatively few long-term gains. While rejecting follow-up sessions as a solution to improving the impact of these sessions, he argues instead for a focus upon activities which raise awareness, one in which teachers can choose their own way forward and find their own changes for their own context.

\subsection{The materials writer}

Johnson (1989: 10) states that there is often a 'difference between actual proficiency levels of learners and levels assumed by materials writers'. This may be the case in Spain, particularly if we take into account what has been previously stated with regards to curriculum writers. However, the introduction of this and the previous law (L.O.G.S.E) have brought along with them a new educational phenomenon. Included in each pack of newly adopted 
course materials for the teacher provided by any of the major publishers in Spain is all the software necessary to copy, cut, paste and modify school curricular projects, units of work and even individual lesson plans. While the present writer does not as yet have any evidence of the extent to which these are used by teachers in Spain, the fact that they are provided systematically by publishers is an important indicator of their demand. This phenomenon of pre-packaged course plans appears to have begun with the nation-wide adoption of previous legislation (L.O.G.S.E.) which was first introduced in 1989 and has been increasingly developed apparently in response to the teachers' need to wade through the bureaucratic demands of the educational administration. While they may prove to be useful to the teacher in many respects, it is possible that the overuse of such complementary material may lead to two unsatisfactory situations: the first of these is that some teachers may use these course plans in a way which reduces their own decision-making processes with regards to the curriculum; the second situation, more frequently observed by this teacher, is that a gap may develop between what is given to local education authorities and what is actually done in class.

\subsection{Teachers?}

This brings us to the final (or primary) protagonists in effective teaching - the teachers themselves. In their search for ways forward, many sit through long intensive hit-and-miss sessions of teacher training, at times spending hours laboriously working through course and lesson plans, some using prefabricated units of work provided by publishers, and others spicing these up with warmers and fillers. Some find time to research and attempt to bridge the gap between theory and practice; others rely on their many years of experience without apparently feeling the need or desire to renovate their pedagogical perspectives. Often, teachers are challenged not only by extreme mixed-ability classes, but also have to deal with pupils with important behavioural problems. Now, it seems, schools and teachers are to be subject to 'voluntary' external assessment by the administration using principles various aspects of which appear to have arisen from Total Quality Management and are now packaged as Quality in Education. In many ways teachers may justifiably feel a deep sense of frustration, and indeed, as recent protests have indicated, resentment in response to these externally imposed changes.

So what can the teacher do in the light of reported lack of confidence in the administration, the lack of satisfaction with in-service training schemes and the failure of previous legislation? Brodie (1983: 49) states that:

In talking about effectiveness, person and context must be considered together. Teachers do not work in isolation. The effectiveness of the teacher may be helped or hindered by the organisational setting. The odds are against a capable teacher working to maximum effectiveness in a hostile atmosphere or in a poorly managed school. Likewise, the best efforts of those responsible for the organisation can be nullified by what happens at the point of contact between teacher and pupil.

It appears evident that in order to become effective, a high degree of collaboration between teachers and other authorities must be achieved. Yet collaboration requires both mutual respect and effective communication, and also a solid knowledge of all external objectives, be they at governmental, school-management or individual pupil levels. The latter does not, however, mean that teachers cannot think for themselves or establish their own 
priorities. In fact, given their privileged 'educated insider' position, it is perhaps time to lend more weight to their views and, as TQM managers would probably put it, empower teachers by placing them at the centre of decision-making processes. This could, perhaps begin with gaining an insight into the principles which have influenced governmental decisions and follow with practical suggestions as to the application of these principles, in this case at least, to the field of ELT in state-funded secondary schools in Spain.

\section{What is Total Quality?}

In order to see a possible way forward in applying principles of Total Quality to formal secondary language instruction, it would seem appropriate at this stage to outline the development of quality systems throughout the world, in Europe and finally in the educational context in Spain. In a global sense, Álvarez (1998: 14) draws upon a number of sources to provide a collection of principles which can be tentatively used to obtain a clearer perspective of quality management (2.1).

Despite its often challenged status, the concept of Total Quality, has enjoyed a much greater degree of familiarity and acceptance in the area of business management than in the field of teaching. Quality Control as we know it today appears to have had its true commercial beginnings in the United States during the period of the First and Second World Wars and had a large impact on the ruined Japanese economy after World War II. In 1988 the European Foundation for Quality Management (EFQM) was founded, building on the successes of previously implemented models while taking into account the idiosyncrasies of the European dimension. Since its initiation, this foundation has endeavoured to apply its own principles to a large number of sectors, including education, with varying degrees of success. These general principles are in turn integrated into a number of criteria that are measured through a process of combined self and external assessment leading to a final score being given to the participating centre.

Total quality programmes claim to provide a number of fundamental strategies and attitudes which, if willingly adopted, are reported to significantly enhance process and/or product systems. Many effectiveness models work on a 'first things first' paradigm (see Covey 1989: 185-232) in the sense that the vision of leadership precedes the achieving of significant results. At the same time, there is a strong emphasis within such programmes of the concept 'win - win' situations, also referred to by Covey (ibid: 262-303), not to mention a high focus of attention on motivating strategies. Finally, it is worth mentioning that there is also a large degree of importance given to the search for continuous improvement strategies. Many of the principles used in TQM and Excellence models have been taken on board by the Spanish government with the introduction of new legislation and also in the public sector in Great Britain, with the creation of governmental organisations such as the Standards and Effectiveness Unit (S.E.U.). The problem with the adoption of these models, however, is that the fundamental role of intrinsic teacher motivation within the evaluative dimensions is not always fully considered. If we add to this the previously mentioned observation that some teachers may see effectiveness models as an imposition from the administration, it is possible that many instructors may be unprepared or unwilling to form part of effectiveness 
Shared Principles of Total Quality

- The client comes first.

- Teamwork and collaboration are essential.

- Customer satisfaction is the most important predictor which appears in all Quality movements.

- Continuous improvement programmes are preferable to quick solutions.

- Decisions must be based on data and communicable evidence.

- Assumptions and postulations cloud decisions.

- Finding solutions is more important than stating problems.

- Managing quality is not an isolated problem; it is a continuous and permanent process of searching for solutions.

- Quality programmes must imply all workers in a voluntary way.

- Total quality is based on people rather than on money. Quality is produced by people.

- Participation in decision-making increases the level of dedication of individuals with the organization and obtains the added value of an improvement in performance.

- Individuals are creative and can be trained to innovate and solve problems.

- Development and personal growth are just as important for the individual as they are for the organisation.

Table 1. Shared Principles of Total Quality (Translated). Taken from M. Alvarez (1998:14)

programmes and hence lose out on the benefits that these can provide both for them and their students.

As far as Quality in Language Instruction is concerned, White (1998: 133-138) attempts to answer the question 'What is quality in English language Teaching?' While pointing out that there has been little published literature on the subject, White provides a brief overview of quality in general and quality in education in particular. It appears, however, that, in this article at least, he does not fully address his original question, nor does he provide examples of any models which are systematically applicable to EFL instruction. He does point out the importance of judging whether the stakeholders prioritise process over product or vice-versa as a decisive factor in opting for a quality system based on continuous improvement (process) or on accountability and quality assurance (product) and mentions the need to find a balance between accountability and autonomy. However, while both White (1998) and Thomas (2003) have made efforts to define Quality and show its place in language instruction, neither has been bold (or unwise) enough to specifically draw a possible roadmap for the individual teacher wishing to engage in effectiveness evaluation.

The objective of the following sections of this paper, therefore is to recognise the fundamental importance teachers can play within the decision-making processes within their own contexts and to offer a possible framework within which these decisions may be taken.

\section{Profesional teachers as key Players in establishing and Sustaining IMPROVEMENT}

Personal and professional development and as well as general improvement of standards are often presented as a cyclical process. Covey (1989: 395-397) argues that renovation is both the beginning and the process where learning, commitment and action should act in a 
continuous upward spiral. In quality assurance models the $\mathrm{PDCA}^{2}$ cycle has been used for many years to implement change in individual areas of improvement in organisations including schools. Similarly, central to the EFQM model is the RADAR ${ }^{3}$ framework of principles seen in Quality in Education (2002b: 'What is the EFQM Excellence Model?'). In English language teaching cyclical models are presented by Pachler \& Field (1997: 322) in the case of professional development and by Johnson (1989: xiii). Among the common denominators in many of these models, we can find the following:

- The search for knowledge based on objective multiple-input sources

- The prioritisation of objectives

- The implementation of improvements

- The systematic assessment of what has been done in order to continuously improve.

However, as is often the case with external assessments by inspection bodies or even voluntary evaluations requested by school management teams, the motivation of the individual teacher in any improvements suggested may, as previously argued, be purely extrinsic. On the other hand, just as Alderson (1992: 276-277) mentions in providing guidelines for the evaluation of language education, even when the motivation to participate in improvement programmes is apparently intrinsic, it may be the case that a number of hidden agendas are in place: these may include the desire to obtain job promotion, or even to earn academic credit. The argument here, however, is that for effective intrinsic motivation to exist, the starting point must lie in the professional concerns of the teacher.

Definitions of teachers as professionals have been provided recently in both general education research as well the specific field of language instruction. Glickman (2002: 87-90) places teachers into four categories based on their level of commitment level of abstraction. These include:

- Teacher dropouts: characterised by their low level of commitment and acceptance of responsibility

- Unfocused workers: while enthusiastic and hard-working, often fail to 'think problems through and then act realistically'

- Analytical observers: can clearly analyse problem situations but are unwilling to carry out improvements

- Professionals: committed and in possession of a high level of abstraction, are able to think about problems, develop various strategies and carry out appropriate improvement for themselves and others.

Another useful perspective on professionalism in the context of the language teacher, is provided by Ur (2002: 388-392). Here, English teachers as professionals are positively contrasted with other interested parties (including amateur English teachers and academics), and are recognised to have a vantage point which allows for both thinking 'in order to improve action' and taking on the role of 'an immediate agent of real-world change' (Ibid: 390).

${ }^{2}$ P.D.C.A Cycle. Plan - Do - Check - Act.

${ }^{3}$ R.A.D.A.R. Determine Results required - Plan and develop Approaches - Deploy approaches - Assess and Review approaches and deployment. 
Again, however, it would be unwise in this interdependent world to see even the professional teacher as an independent agent of change. Not only do 'Quality' movements such as the E.F.Q.M. rely on the benchmarking of good practices; the importance of sharing experience in order to establish and sustain improvement is also of fundamental importance to general education bodies such as O.C.E.D and specifically English language teaching organisations such as the British Council.

\section{TOWARDS EFFECTIVENESS IN LANGUAGE INSTRUCTION}

Taking into account what has been said previously, it could be asked how language teachers could begin to examine their professional dedication in a structured way. The following section of this paper suggests a possible general framework which may contribute to individual or departmental effectiveness in language instruction and could be compatible with the introduction of recent legislative changes in Spain. As I mentioned previously, this is a tentative view of how things might be and while individual elements of this framework have been implemented by the present writer and others, the process as a whole remains to be put to the test. Special consideration is given to a number of areas (shown in figure 4.1), which are seen as fundamental to enabling systematic improvement. At the same time, it would also be important to state that while the framework is presented at a macro or whole system level, it is argued that the suggested steps are equally applicable to micro or individual areas of improvement.

Figure 1. Diagram of proposed effectiveness model 


\section{Step 1: Motivation}

In order to encourage effectiveness in language teaching and learning, perhaps the most important element is that of motivation. Much has been said in both in general education and in modern language teaching and learning research about student motivation. It is generally accepted that for learners to maximise their potentials or, for that matter, to even have a desire to learn, there must be a series of inbuilt motivating elements within the learning process. In general education terms, Byrnes (2001: 118-119) suggests a number of general considerations to increase motivation, which includes helping students setting appropriate goals, providing systematic feedback to allow pupils to monitor their degree of progress and providing activities which allow learners of all abilities to feel competent and realistically challenged. In the field of SLA, Ellis (1994: 508-517) draws on a number of sources to provide solid arguments which support the adoption of attitudes and inclusion of activities which increase learner motivation; among these, he links high motivation with perseverance and achievement. However, there seems to have been relatively less investigation in applied linguistics which has taken into account the real need for teacher motivation in the language class. Does this mean that English teachers are by nature highly motivated people?

Business consultant Richard Denny (2000: 15) states, in outlining his 'Laws of motivation', that in order to motivate, we must be motivated and it would not seem unnatural to assume that as 'classroom managers', teachers themselves should have a high level of enthusiasm for what they are doing. In order to improve motivation, a number of things can be suggested. Firstly, if we listen to what non-linguist motivation experts have to say, we can tentatively identify a number of principles. Denny (ibid: 14-26) provides a useful starting point in this sense in stating that, among other factors, motivation requires having goals, recognition, group belonging, visible progress and participation. In the field of educational psychology applied to language instruction Williams \& Burden (2000: 141-142) provide a number of important considerations, some of which coincide with previously mentioned factors (table 2). It is true that the provision of such a list of factors may help the teacher to take into account student motivation, but who is to ensure teacher motivation and how many of the factors presented below are equally applicable to teachers?

1. Recognise the complexity of motivation

2. Be aware of both initiating and sustaining motivation

3. Discuss with the learners why they are carrying out activities

4. Involve the learners in setting language learning goals

6. Recognise people as individuals

7. Build up individuals ${ }^{\prime}$ beliefs in themselves

8. Develop internal beliefs

9. Help to move towards a mastery orientated style

10. Enhance intrinsic motivation

11. Build up a supportive learning environment

12. Give feedback that is informational

Table 2. Factors in student motivation. Williams, M. and R.L. Burden. (2000). 
If we compare all of this with the educational framework with which we are dealing, it could be argued that certain provisions are made, in word at least, with motivating the professionals involved in teaching. In comparing the above table to the references made to instructors in L.O.C.E. and previous laws still in place, we could argue that teachers evidently have a detailed set of goals. At the same time, Article 1.h) of L.O.C.E. mentions the giving of recognition to teachers and takes into account the promotion of teachers within schools, indeed this constitutes one of the 'Principles of Quality' (B.O.E. 307: 45188) and shows the insistence of the administration in systematising recognition within the educational organisation. Yet while there have been considerable advances in terms of including systems of extrinsic encouragement within new legislation, they still remain just that: extrinsic. In this sense, a model that could be more successful would be one in which language instructors could:

a) systematically incorporate their own realistically attainable yet challenging goalsetting procedures based on their specific instructional context

b) provide themselves with recorded goals and measure the completion of such goals in order to see their own progress

c) identify their own training needs and establish ways of fulfilling them

d) create a sense of group participation in their search for improvement for all involved in the process

e) encourage the systematic improvement of processes in order to facilitate teaching and learning

f) provide each other with tools to investigate and encourage more favourable teaching strategies

g) focus on the specific needs of formal language instruction

All of this would perhaps require the implementation of a future framework to systematically incorporate the above-mentioned motivational considerations at its core.

The key here, however, is not only to create the motivational conditions which allow teachers to reflect and improve, but to permit sustainable systematic effectiveness. The biggest challenge in this sense is that many teachers are already overburdened the daily stresses of instruction, planning and assessing and may feel that they do not have the time to engage in what is essentially a form of action research. Two considerations, therefore, to be discussed at later stages are firstly, the need to prioritise areas of improvement so that actions taken are both important and viable, and secondly, that improvements in processes should be aimed at preventing and/or reducing unnecessary time-consuming activities.

\section{Step 2: Analysis of situation}

Before embarking upon any type of improvement programme, it would appear both intuitively and by examining current practices in effectiveness models that the first step towards betterment lies in the analysis of the areas to be improved. While individual language contexts may share a large areas of common ground (not least of which is that embodied in objectives outlined by the administration), each language learning context is unique. Analysis of the context may take a number of forms, but it would seem necessary to employ a model of self-assessment which simultaneously takes into account what is widely used in effectiveness programmes in education in general as well as current trends in language teaching while 
allowing the individual participants to effectively address their own instructional contexts. The key aspects to be considered could be governmental requirements, analysis of teacher context (good points, areas of improvement and objectives), analysis of learner context (good points, areas of improvement and objectives), identification and improvement of key processes and analysis of resources (text books, audio-visual and other resources). Among possible areas of knowledge the following would appear to be fundamental for the professional teacher:

\section{a) Solid knowledge of the official educational framework}

Keeping up to date with legislative developments affecting teaching and learning would appear to be the first and most important area of knowledge for the state employed teacher. Even when there is evidence (either hearsay or empirical) presented to show that governmental objectives may not be realistically presented, it is argued here that they still represent an important perspective with regards to the establishment of important goals and the search for the fulfilment of the same.

\section{b) Information received through self-questioning}

But before any decisions about language teaching are made, the first component that should be analysed lies in the teachers themselves. It is not enough to be fully informed of students' linguistic or motivational levels or, indeed of governmental or managerial guidelines. All of this information would, by definition, be incomplete to a truly reflective language teacher. Nonetheless, the views of both teacher and government do not necessarily have to be at odds, indeed, in the search for improvement, a large area of common ground should be found. On the other hand, there may be a sense that teachers have a tendency to feel that they are treated as mere technicians, blindly following ministerial instructions without being able to think for themselves, when this does not have to be the case. Among other aspects, a number of considerations to be examined with a view to improving weak areas could be those identified in a self-assessment questionnaire, a translated example of which is provided at the end of this paper (Appendix I). While the particular instrument presented has been designed with the help of a number of teachers and research supervisors, like the other instruments provided, it is not intended to be prescriptive, but instead to encourage reflection.

\section{c) Knowledge of management expectations}

By maintaining effective communication with school management it is possible to identify what is expected of you as a teacher as well as obtaining another source of advice upon how to set and reach objectives. At the same time, in the context of recent legislative changes, it is likely that an increasing number of schools decide to embark upon 'Quality' management frameworks which may offer individual teachers the opportunity to develop their knowledge of the implementation of such models.

\section{d) Information received through students}

Decisions about how to present the 'best' learning experience for a group of students inevitably depends on the individual teacher's ability to work out what those students appear to need, while also remaining aware of what they expect to happen in the learning situation.

Tarone, E. and G. Yule. (1989:9) 
Self-questioning provides only the first step to self-knowledge. It may be seen as useful to possess student profiles before planning coursework, this would be particularly true in the case of linguistic competence, since as we shall see later, one of the major motivational stumbling blocks for students may arise from imposed objectives that are either too far above or below their ability levels or from instruction which fails to take into account their interests, beliefs or learning styles. In addition to these factors, however, another important aspect of student context is that of identifying specific factors which may help build awareness of individual and collective psychological factors such as motivation and anxiety (Tarone \& Yule 1989: 133-138) and hence consider these at the planning stage of activities. The essential message here is that student profiling through questionnaires can represent a step towards knowing our students as well as how they feel about certain matters, about what intrinsically motivates them and, just as important, what does not. This knowledge gives us the opportunity to become more empathetic teachers while simultaneously providing us with another set of indicators and items of information with which to plan and hence more successfully allow for the completion of objectives. A particularly useful set of instruments to measure various aspects of learners views in the context of secondary level EFL in Spain is provided by Madrid (1999: 83-103).

\section{e) Information received and exchanged through ELT specific sources}

Fortunately, a number of ELT information sources are widely available nowadays to teachers either through conferences, in-set training courses, on-line ELT organisations and local universities. Networking, used for example by the British Council also provide forums for the exchange of information good practice. It is argued here that participation in such activities and / or organisations could serve not only as a way of updating skills and knowledge, but also act as a source of motivation.

\section{Step 3: Establish Goals}

Joyce et al. (1999: 81) state that 'the primary goal of evolutionary school improvement is enhanced student learning' and continue by saying 'however, a healthier workplace for adults often evolves'. Goals may appear from many different areas, from the curriculum or from hidden curricula, from management or even from parents. Yet while the voices of all stakeholders should be taken into account, it is argued here that for real progress in learning to take place the goals set must arise from the students themselves with the guidance of the professional teacher. Yet for this to occur, it would seem necessary to have high levels of both professionalism and motivation on the part of instructors. In the end, it is the individual teacher who must attempt to balance objectives, be they internal or external to the class. What follows, therefore, is a list of a number of fundamental stakeholders potentially involved in establishing objectives, followed by a possible outline as to how the process of goal setting may take place within an improvement framework.

\section{a) Objectives from external stakeholders}

In mentioning external objectives, I refer to type of goal which we are externally 'encouraged' to achieve, be they governmental, in the form of minimum objectives for secondary school learners, or a minimum standard of examination results in EFL tests. At this stage, 
suffice it to say that in all of our planning, we cannot fail to take into account our own professional responsibilities, though at the same time we cannot ignore all of the other contextual considerations that have been previously mentioned.

\section{b) Teachers' objectives}

In order to arrive at a certain destination, it is paramount to state what our destination should be in the clearest possible terms, or as Covey (1989: 121-124) puts it, 'to start with an end in mind'. It is only by having our own solid ideas as to where we wish to go that we can obtain a better idea as to how to get there, the motivation to keep us going and the possibility of ascertaining whether or not we have arrived. This idea is fundamental in all professions in which success is judged by performance and completion of objectives. Indeed, it is a fundamental concept of business management and often determines whether or not a professional stays within the profession, climbs the ladder of success or is simply asked to find another job. It is also necessary to have a clear set of objectives if we, as teachers, are to expect our own pupils to have intrinsically motivating goals to encourage them forward in their acquisition of another language.

\section{c) Learner goals}

In many cases, the feeling of competence is largely responsible for either the creating or destroying of the powerful learning vehicle of motivation. The idea that a student needs to feel confident and competent is by no means new. Indeed, it has a lot to do with the way in which objectives must be within the range of possibilities of each individual learner. Vygotsky's Zone of Proximal Development (ZPD) theory provided an early insight into the need for staged learning so that learners could gradually build upon previous knowledge without aiming for unreachable objectives while at the same time giving students enough to allow them to feel sufficiently challenged. In the area of psychology in language learning, Williams \& Burden (2000: 138) mention achieving 'an optimal degree of challenge' as an intrinsic factor of learner motivation. More recent and specific examples of proximal goal setting can be seen in studies such as Nation's (2001: 165) research into vocabulary acquisition, where we are informed that 'learning from meaning-focused input can best occur if learners are familiar with at least $98 \%$ of the running words'.

\section{d) The improvement of processes}

A process can be defined as the logical organisation of people, materials, energy, equipment and procedures into work activities designed to produce a specified end result.

\section{G. Pall (1987)}

It may seem to be stating the obvious in saying that in order to achieve different results it is necessary to change the methods employed to achieve them; in this sense, it is proposed in quality models such as the EFQM that the identification, improvement and implementation of key processes are extensively linked to the improvement of results. It would perhaps be useful to outline a number of areas to aid participants in improvement groups to pinpoint the 
key processes involved in their specific context. For this reason a number of possible processes are mentioned at the end of this document (Appendix II). These processes are neither prescriptive nor exhaustive, but instead are intended to provide a general view of the identification of processes for their future assessment and possible improvement.

\section{e) The process of goal setting}

While goal-setting is not new to language teaching, many of the processes used today in both business and school management (particularly in countries where effectiveness activities have been long established) may well be unfamiliar to many involved in formal language instruction in Spain. A particularly useful tool may be one which allows various members to prioritise areas for improvement based on both the perceived importance and viability of such actions (Appendix III). In this particular instrument, a group of teachers would examine a set of areas marked for improvement, assign each area a score based on its importance and viability and then sum the scores in order to obtain a clearer perspective as to where group priorities may lie.

\section{Step 4: Design strategies}

Designing strategies for improvement require not only interpersonal skills but also a certain knowledge of organisational strategies. Once an area is earmarked for improvement a number of such strategies, some of which are already familiar to the majority of English teachers, can be employed. A number of suggestions are outlined below.

\section{a) Brainstorming}

Among the benefits for brainstorming ideas in teams are that participants provide a multi-sourced perspective on possible solutions, allowing individual innovation to flow. The key to using this technique is arguably in being able to prioritise realistic and viable actions for improvement while taking into account that more than one action may be needed to be used in order to obtain the desired results. A useful description of the brainstorming process is provided by Breyfogle (1999:78-79).

\section{b) Spine Diagram}

Commonly used in TQM movements and attributed to Dr. Kaoru Ishikawa (see Ishikawa 1985: 16-26) the purpose of this slightly adapted instrument, is to find sources of problems in an organised way, taking into account the major stakeholders or factors affected by or contributing to the problem (see figure 2). This diagram can be further extended (on larger surfaces e.g. blackboard) to include possible general solution statements to the problem, such as 'design vocabulary improvement strategy', in the case shown below. 


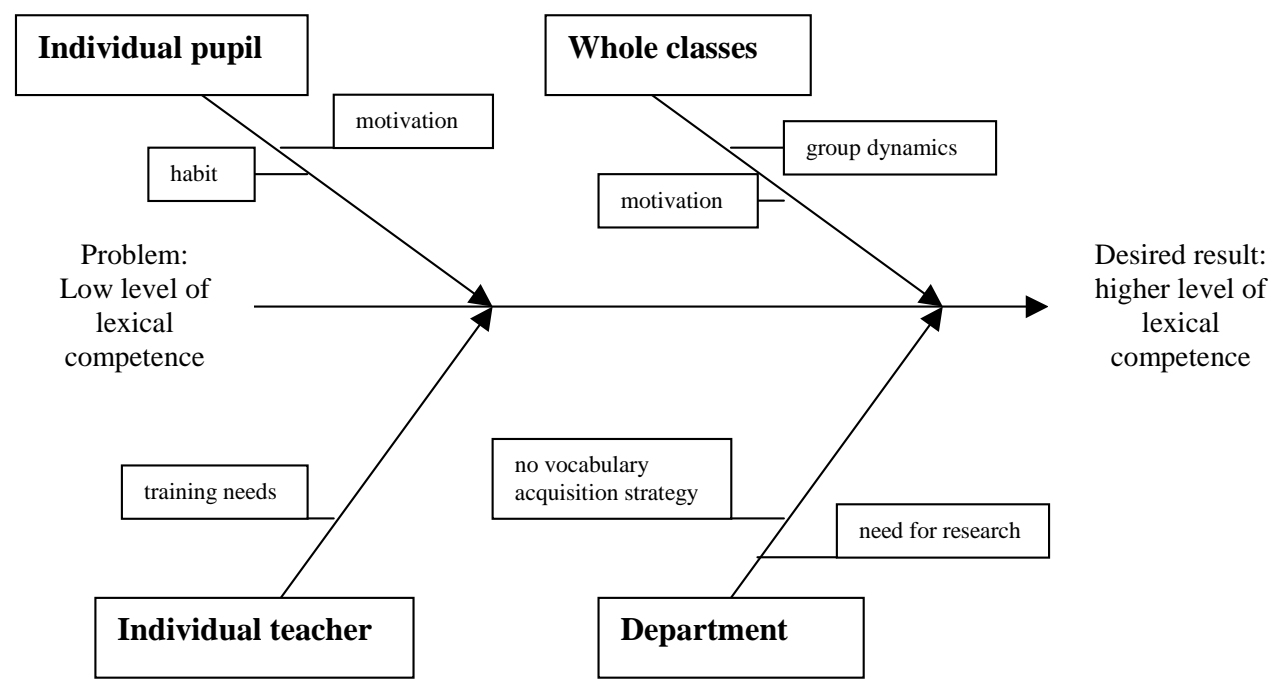

Figure 2. Example of Spine Diagram

\section{c) Results-cause-solutions table}

Going to the root causes of problems may contribute to the improvement not only of specific cases, but also of more general areas of improvement. Thus in the above imagined diagram, it may be argued that one of the prime causes of general low levels of lexical competence arises in the failure of the department to have a vocabulary acquisition strategy. A results-cause-solutions table is a simple instrument used to examine the situation, find the causes and establish viable solutions (see Table 3 ).

\begin{tabular}{|l|l|l|}
\hline Results / Present state of affairs & Causes & Solutions \\
\hline & & \\
\hline & & \\
\hline & & \\
\hline & & \\
\hline
\end{tabular}

Table 3. Results-causes-solutions table

Once strategies have been designed, it is then a case of deciding the who's, how's, where's, what's and when's of implementing decisions made by the group involved. It is also at this stage that decisions are made with regards to the inclusion or not of control measures to provide formative and summative assessments of improvements undertaken as well as documentation of the various stages of the process. Answers to these questions would largely depend upon the amount of time and resources available to groups, as well as the groups ability to delegate tasks though the empowerment of stakeholders, including students. 


\section{Step 5: Implement Strategies}

Identifying weak areas is but the first step towards improvement, but if no subsequent actions are taken then the same weak areas will remain. At the same time, if actions taken are not effective, then participants may experience a sense of futility having invested time and effort into a task that has proved worthless. It is suggested here that the following factors may influence the outcomes of improvement efforts:

- Is there knowledge on the part of participants of improvement strategies?

- Do participants know which strategy to use when?

- Given the nature of the problem and taking into account the limitations on human resources, are those involved in the implementation of specific strategies the most appropriate participants?

- Have improvements been prioritised according to Importance and Viability?

- Have strategies been sufficiently planned?

- Are steps taken to record strategy use as well as measurements of success of such strategies in order to learn from past experience and establish markers of success?

- Does the implementation of strategies take on board the opinions of the main stakeholders both in identifying the problem and working on the solution?

- Is the purpose of the strategy known and can progress in the strategy be seen by all stakeholders?

- Are all participants in implementation of strategies given recognition for their efforts?

In improvement programmes, the implementation of strategies plays a central role. An instrument intended to aid strategy implementation is provided at the end of this paper (Appendix IV). This suggested procedure is aimed at organising strategies in a coherent way while taking into account the importance of recognition of all involved in the improvement process. In essence, this procedure reflects the general format of the entire improvement plan, although working on a much smaller scale, in that it begins with the assessment of needs, continues with suggested strategies and ends with a control over the results of the process.

\section{Step 6: Focus on results}

The focus on results can take a number of areas into account. Five areas are suggested below (table 4). The challenge here is to find objective and reliable and time-efficient instruments of measurement without damaging intrinsic motivation.

In terms of the results obtained by the implementation of improvement strategies, it is suggested here that there are four basic areas of assessment:

a) What were the original objectives of this improvement project and to what degree have they been achieved?

b) Which improvement plans worked and to what degree?

c) Which improvement plans failed and why?

d) What implications does this have for future improvement projects?

The question as to who should judge the effectiveness of an improvement plan depends to a large degree on the nature and context of the implementation. It is possible that an 


\begin{tabular}{|l|l|}
\hline Area of focus & Possible measurement tools \\
\hline Academic achievement of students & Assessment results, proficiency tests \\
\hline Perceived motivation of students & Questionnaires, interviews, observation \\
\hline Teacher performance & Student results, observations, interviews \\
\hline Teacher motivation & $\begin{array}{l}\text { Questionnaires, interviews, observable indicators such as } \\
\text { absence etc }\end{array}$ \\
\hline Results of improvement strategies & $\begin{array}{l}\text { Questionnaires, assessment of implemented areas of } \\
\text { improvement and ascertainment as to whether individual } \\
\text { \& general objectives have been achieved }\end{array}$ \\
\hline
\end{tabular}

Table 4. Possible tools for measurement of results

individual teacher may wish to 'go it alone' in attempting to improve processes and even carry out the assessment individually. This however, has a number of serious drawbacks. Firstly, by failing to call upon the perspectives of others, the process is likely to be both subjective and skewed. Second, such a decision would mean that the burden of implementing all stages, including assessment, would fall on the shoulders of one person. If implementation were carried out by a team such as a department, the process would naturally be enriched by a variety of perspectives and would arguably lead to more effective decisions being taken. Yet further information could be obtained from individuals or groups from outside the department; this could include other departments, school management, teacher support groups, experts in general or language pedagogy or even inspectors. According to Alderson (1992: 279) both insiders and outsiders should form part, not only of the assessment process itself, but of all other processes introduced. Among the benefits mentioned by Alderson (ibid: 279) are that outsiders may play an important impartial role when there is division of opinion between insiders while possibly offering technical expertise. Alderson (ibid: 280) also mentions the fact that sometimes expertise in other fields, such as statistics or management is required, although again, this would depend the size and scope of the project.

\section{Step 7: Improve the improvement process}

At the stage of improving processes, and provided that information has been recorded throughout implementation, two large bodies of data would be available. The first of these is the information collected during the 'analysis of the situation' and 'objectives setting' stages. This serves not only to compare objectives and results at the end of an implementation stage, but also acts as a record of objectives, including the often more elusive long-term goals. At the same time, the recording of both successful and unsuccessful attempts at improving areas provides a clearer picture with regards to what specific tools and strategies have and have not worked. This allows for the building of knowledge upon previous experience while allowing for the refinement, adoption or elimination of strategies for future areas of improvement. As initially stated, the development of improvement systems often work on a cyclical or upwardly-spiralling basis. In this case, it is suggested that the final stages of examining results and improving the process flow naturally back into the stage of analysis of the situation and continuous search for improvement. 
As far as the empirical testing of such an improvement model, a number of researchers have either simply avoided the question or have rejected it as impossible. Joyce et al. (1999), while receiving significant recognition for their work on developing school improvement, have at times come under criticism for not presenting empirical data. Perhaps in response to this, they indicate the need to reform educational systems of reform by embedding action research into management stating:

the study of what happens when an initiative is conceived needs to be built into the initiative itself: not a summative evaluation by an external agency but an ongoing collection of data and a periodic review on those data with an eye on how to improve the initiative.

$$
\text { Joyce. B, Calhoun, E., and D. Hopkins. (1999: 215) }
$$

Similarly, Kember (2003: 99-100) in examining the viability of experimental designs on improvement models in higher education states:

... experimental designs are not often suited to evaluating the effectiveness of teaching innovations in higher education. Instead of using experimental designs with the (probably illusory) aspiration of showing causation, teacher-researchers might more reasonably aim to establish claims beyond reasonable doubt. The commonly used principles are of triangulation of data from a variety of sources obtained by several methods. The advantage of such evaluation designs is that they do provide formative evidence for fine tuning, which is at least as important as summative data obtained with the aim of showing effectiveness.

Kember (2003: 99-100)

At the same time, Kember (ibid: 100) referring to Kember (2002) mentions that in a study of 90 action-research innovation programmes all the participants.

... experienced a lasting improvement in their teaching, a knowledge of how to conduct action research, development of their capacity to monitor and reflect upon their own teaching and better teamwork skills.

Kember (ibid: 100)

It seems therefore that experimental design would prove both difficult and unwieldy if not genuinely impossible. This does not mean to say that the successes and failures of implementation of such projects can point to reasons which justify the continuation or ending of the same. Nor does it mean that individual groups of teachers cannot share their views in order to find a better way forward.

\section{Communication of achievements}

Like the rest of the activities mentioned up until now, the communication of achievements obtained through the implementation of an improvement model would depend largely on the scale and scope of the project. Perhaps the most immediate groups to receive such information would be the principal stakeholders, including students and participating teachers. Other 
members of the school community may also be interested in knowing about how improvements came about and indeed, offer further advice on how to better the process. On a wider scale, the sharing of successful innovation between ELT groups and organisations could provide a series of mutually enriching exchanges of information. Another important by-product of communicating achievements is the potential increase in motivation of exponents through their participation and the recognition which is obtained in the process.

\section{Conclusion}

In this Paper I have attempted to provide what I have seen as a number of fundamental considerations to be taken into account in my own search for more effective ways to teach my students in the specific context of state secondary level English teaching in a country undergoing profound educational change. At the same time I have attempted to provide possible areas of thought for teachers who may also be interested in adopting holistic frameworks to improve all areas of their teaching. While this study is based partly on my experience as a teacher, partly on my training as a quality co-ordinator and partly as the initial stages of a research project, the findings do not form part of an empirically proven hypothesis. For this reason I have mentioned at several times in this paper that the areas presented are to be examined critically, and if any of the proposals prove useful, they should both be adjusted to the context and evidence should be sought for their effectiveness.

For this teacher at least, the search effectiveness does not end here, indeed, as previously indicated, the title of this paper suggests moving towards the construction of a framework and the hope is that some of the groundwork has been done. The intention now is to put what has been said to the test through case studies in the context in question, to disseminate any useful findings where possible and, in the spirit of effective practice, to take on board suggestions from all sectors with the view to continuously improving the improvement process.

\section{BibliogRAPHY}

Alderson, J. C. \& M. Scott (1992). 'Insiders, outsiders and participatory evaluation.' in J.C. Alderson \& A. Beretta (eds.), Evaluating Second Language Education. Cambridge University Press.

Alderson, J. C. (1992). 'Guidelines for the evaluation of language education.' in J.C. Alderson \& A. Beretta (eds.), Evaluating Second Language Education. Cambridge University Press.

Álvarez, M. (1998). El Liderazgo de la Calidad Total. Editorial Escuela Española.

Barquín, J. \& J. Fernández (1998). 'Las perspectivas de asesores y profesorado sobre formación permanente. Avance de una investigación en curso'. La Formación del Profesorado. Evaluación y Calidad. Universidad de las Palmas de Gran Canaria.

Breyfogle, F.W. (1999). Implementing Six Sigma. Smarter Solutions Using Statistical Methods. John Wiley \& Sons Inc.

Brodie, M. (1983). 'Understanding Organization and Management'. In A. Paisey (ed.), The Effective Teacher. Ward Lock Educational.

Byrnes, J. P. (2001). Cognitive Development and Learning. Allyn \& Bacon. 
Covey, S. R. (1989). Los Siete Hábitos de la Gente Altamente Efectiva. Ediciones Paidós Ibérica. Original title: The Seven Habits of Highly Effective People. Simon and Schuster.

Denny, R. (2000). Motivate to Win. RDO Publications.

Ellis, R. (1994). The Study of Second Language Acquisition. Oxford University Press.

Glickman, C. D. (2002). Leadership for Learning: How to Help Teachers Succeed. Association for Supervision and Curriculum development.

González, M.C.; Iniesta, A.; Martín, J.; Nieda, J.; Prada, M.D.; Urbón. F. (1995). Evaluación del Profesorado de Educación Secundaria. Ministerio de Educación.

Ishikawa, K. (1985). Guía de Control de Calidad. Unipub. Original title: Guide to Quality Control. Asian Productivity Organisation.

Johnson, K (Ed) (1989). 'A decision-making framework for the coherent language curriculum'. The Second language curriculum. Cambridge University Press.

Joyce. B, Calhoun, E., Hopkins, D. (1999). The New Structure of School Improvement: Inquiring Schools and Achieving Students. Open University Press.

Kember, D. (2002). 'Long term outcomes of educational research projects. Educational Action Research. 10 (1): 83-103.

Kember, D. (2003). To control or not to control: the question of whether experimental designs are appropriate for teaching innovations in higher education. Assessment \& Evaluation in Higher Education. Volume 28, $\mathrm{N}^{\circ} 1$ : 89-101. Carfax Publishing.

Lamb, M. (1995). 'The consequences of inset' ELT Journal, 49 / 1: 72-80.

Madrid, D (1999). La Investigación de los Factores Motivacionales en el Aula de Idiomas. Grupo Editorial Universitario. Dpto de Didáctica de la Lengua y Literatura, Universidad de Granada.

Nation, I.S.P. (2001). Learning Vocabulary in Another Language. Cambridge University Press.

Tarone, E. \& Yule, G (1989). Focus on the language learner: Approaches to Identifying and Meeting the Needs of Second Language Learners. Oxford University Press.

Thomas, H. (2003). 'The arguments for and the meaning of Quality' ELT Journal 57/3: 234-241. Oxford University Press.

Ur, P. (2002). 'The English teacher as professional' in J.C. Richards and W.A. Renandya (eds.), Methodology in Language Teaching: An Anthology of Current Practice. Cambridge University Press.

Welsh \& Metcalf.(2003). 'Cultivating faculty support for institutional effectiveness activities: Benchmarking best practices'. Assessment \& Evaluation in Higher Education. Volume 28, $\mathrm{N}^{\mathrm{o}} 1$ : 33-45. Carfax Publishing.

White, R. (1998). 'What is quality in English Language Education?' ELT Journal. 52/2 : 132-138. Oxford University Press.

Williams, M.\& Burden, R.L. (2000). Psychology for Language Teachers: A Social Constructivist Approach. Cambridge University Press.

\section{Other sources}

\section{Manuals}

CECE-ITE (1997). Calidad en Educación. CECE-ITE.

Lloyds TSB (2002a). Quality in Education (Booklet): School Self-assessment Using the Excellence Model and Improvement Techniques. Lloyds TSB.

Lloyds TSB (2002b). Quality in Education (Software): School Self-assessment Using the Excellence Model and Improvement Techniques. Lloyds TSB. 


\section{ApPendix I- Suggested teacher SELf-ASSESSMent}

\section{$1=$ no, not much $2=$ below average $3=$ average $4=$ above average $5=$ high/excellent}

\begin{tabular}{|c|c|c|c|c|c|c|c|c|c|c|c|}
\hline \multirow{2}{*}{1} & \multirow{2}{*}{ My level of motivation as a teacher } & \multicolumn{5}{|c|}{\begin{tabular}{|c|} 
IMPORTANCE FOR ME AS A \\
TEACHER
\end{tabular}} & \multicolumn{5}{|c|}{$\begin{array}{c}\text { ASSESSMENT OF THE } \\
\text { PRESENT STATE OF AFFAIRS } \\
\end{array}$} \\
\hline & & 1 & 2 & 3 & 4 & 5 & 1 & 2 & 3 & 4 & 5 \\
\hline 2 & My continuous professional development & 1 & 2 & 3 & 4 & 5 & 1 & 2 & 3 & 4 & 5 \\
\hline 3 & My level of course planning & 1 & 2 & 3 & 4 & 5 & 1 & 2 & 3 & 4 & 5 \\
\hline 4 & The level of support I receive from the school & 1 & 2 & 3 & 4 & 5 & 1 & 2 & 3 & 4 & 5 \\
\hline 5 & The level of support I receive from parents & 1 & 2 & 3 & 4 & 5 & 1 & 2 & 3 & 4 & 5 \\
\hline 6 & The motivation of my students & 1 & 2 & 3 & 4 & 5 & 1 & 2 & 3 & 4 & 5 \\
\hline 7 & The level of student co-operation in class & 1 & 2 & 3 & 4 & 5 & 1 & 2 & 3 & 4 & 5 \\
\hline 8 & The level of recognition I receive from the school & 1 & 2 & 3 & 4 & 5 & 1 & 2 & 3 & 4 & 5 \\
\hline 9 & $\begin{array}{l}\text { If evidence exists, the perceived level of positive stimuli my students } \\
\text { receive in class }\end{array}$ & 1 & 2 & 3 & 4 & 5 & 1 & 2 & 3 & 4 & 5 \\
\hline 10 & The resources available for my classes & 1 & 2 & 3 & 4 & 5 & 1 & 2 & 3 & 4 & 5 \\
\hline 11 & The effectiveness of departmental meetings & 1 & 2 & 3 & 4 & 5 & 1 & 2 & 3 & 4 & 5 \\
\hline 12 & My medium and long-term objectives as a teacher & 1 & 2 & 3 & 4 & 5 & 1 & 2 & 3 & 4 & 5 \\
\hline 13 & The medium and long-term objectives of the department & 1 & 2 & 3 & 4 & 5 & 1 & 2 & 3 & 4 & 5 \\
\hline 14 & $\begin{array}{l}\text { The medium and long-term objectives of the government in terms of } \\
\text { EFL }\end{array}$ & 1 & 2 & 3 & 4 & 5 & 1 & 2 & 3 & 4 & 5 \\
\hline 15 & The medium and long-term objectives of the school in terms of EFL & 1 & 2 & 3 & 4 & 5 & 1 & 2 & 3 & 4 & 5 \\
\hline 16 & The objectives of students with regards to the language & & 2 & 3 & 4 & 5 & 1 & 2 & 3 & 4 & 5 \\
\hline 17 & The development of departmental plans for improvement & 1 & 2 & 3 & 4 & 5 & 1 & 2 & 3 & 4 & 5 \\
\hline 18 & The revision of departmental objectives & 1 & 2 & 3 & 4 & 5 & 1 & 2 & 3 & 4 & 5 \\
\hline 19 & My use of resources in class & 1 & 2 & 3 & 4 & 5 & 1 & 2 & 3 & 4 & 5 \\
\hline 20 & The degree of responsibility students demonstrate in tasks & 1 & 2 & 3 & 4 & 5 & 1 & 2 & 3 & 4 & 5 \\
\hline 21 & The variety of tasks in mv classes & 1 & 2 & 3 & 4 & 5 & 1 & 2 & 3 & 4 & 5 \\
\hline 22 & The promotion of creativity in my class & 1 & 2 & 3 & 4 & 5 & 1 & 2 & 3 & 4 & 5 \\
\hline 23 & The establishment of contact between students and native speakers & 1 & 2 & 3 & 4 & 5 & 1 & 2 & 3 & 4 & 5 \\
\hline 24 & The work carried out by students at home & 1 & 2 & 3 & 4 & 5 & 1 & 2 & 3 & 4 & 5 \\
\hline 25 & $\begin{array}{l}\text { The use of computers as a language acquisition resource by students } \\
\text { in my class }\end{array}$ & 1 & 2 & 3 & 4 & 5 & 1 & 2 & 3 & 4 & 5 \\
\hline 26 & The use of pair and group work in class & 1 & 2 & 3 & 4 & 5 & 1 & 2 & 3 & 4 & 5 \\
\hline 27 & The attention I give to the subjective needs of students & 1 & 2 & 3 & 4 & 5 & 1 & 2 & 3 & 4 & 5 \\
\hline 28 & The attention I pay to diversity in the class & 1 & 2 & 3 & 4 & 5 & 1 & 2 & 3 & 4 & 5 \\
\hline 29 & The perceived level of confidence of pupils when facing tasks & 1 & 2 & 3 & 4 & 5 & 1 & 2 & 3 & 4 & 5 \\
\hline 30 & The use of strategies by students in facing tasks & 1 & 2 & 3 & 4 & 5 & 1 & 2 & 3 & 4 & 5 \\
\hline 31 & The mastery my students obtain in speaking & 1 & 2 & 3 & 4 & 5 & 1 & 2 & 3 & 4 & 5 \\
\hline 32 & The mastery my students obtain in listening & 1 & 2 & 3 & 4 & 5 & 1 & 2 & 3 & 4 & 5 \\
\hline 33 & The mastery my students obtain in reading & 1 & 2 & 3 & 4 & 5 & 1 & 2 & 3 & 4 & 5 \\
\hline 34 & The mastery my students obtain in writing & 1 & 2 & 3 & 4 & 5 & 1 & 2 & 3 & 4 & 5 \\
\hline 35 & The mastery my students obtain in pronunciation & 1 & 2 & 3 & 4 & 5 & 1 & 2 & 3 & 4 & 5 \\
\hline 36 & The mastery my students obtain in grammar & 1 & 2 & 3 & 4 & 5 & 1 & 2 & 3 & 4 & 5 \\
\hline 37 & The mastery my students obtain in vocabulary & 1 & 2 & 3 & 4 & 5 & 1 & 2 & 3 & 4 & 5 \\
\hline 38 & The treatment I give to cultural awareness & 1 & 2 & 3 & 4 & 5 & 1 & 2 & 3 & 4 & 5 \\
\hline
\end{tabular}

Other items I would add to this questionnaire

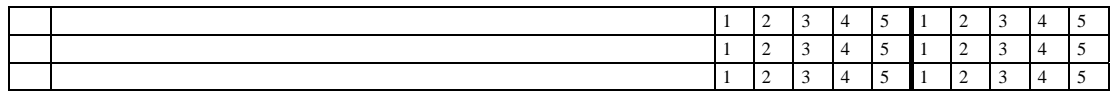

Score the following between 1 (low) and 5 (high) according to the degree of importance and assessment you give to each item. The test is structured in such a way that the closer items appear on the document, the higher priority they have (i.e. if you mark the first item as having an importance for you of $\mathbf{5}$ and an assessment of the actual state of affairs as $\mathbf{1}$, this would have a high priority). 


\begin{tabular}{|c|c|c|}
\hline \multicolumn{2}{|r|}{ CLASSROOM PROCESSES } & OUT OF CLASS PROCESSES \\
\hline 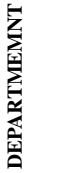 & - Peer observation & $\begin{array}{ll}\cdot & \text { planning } \\
\cdot & \text { target setting } \\
\cdot & \text { departmental meetings } \\
\cdot & \text { decision-making }\end{array}$ \\
\hline 产 & $\begin{array}{l}\text { - } \text { processes to encourage } \\
\text { - } \text { intonatence in } 4 \text { skills } \\
\text { - } \text { grammatical competence } \\
\text { - } \text { vocabulary acquisition } \\
\text { - use of English in class } \\
\text { - general classroom management } \\
\text { - } \text { transvers procedures } \\
\text { - } \text { systematic differentiation } \\
\text { - strategy training } \\
\text { - cultural awareness. } \\
\text { - student satisfaction } \\
\text { - } \text { use of resources }\end{array}$ & $\begin{array}{l}\text { - } \text { course planning } \\
\text { - unit \& lesson plans } \\
\text { - } \text { identificaurce of training needs } \\
\text { - correcting } \\
\text { - } \text { assessment } \\
\text { publications or participation in } \\
\text { conferences } \\
\text { target setting }\end{array}$ \\
\hline 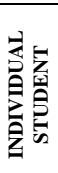 & $\begin{array}{ll} & \text { work in class } \\
\text { - } & \text { participation in class } \\
\text { - } & \text { presentation of work } \\
\text { - } & \text { participation in English } \\
\text { - } & \text { target setting } \\
& \text { strategy use }\end{array}$ & $\begin{array}{ll} & \text { homework } \\
\text { revision strategies } \\
\text { participation in extra-curricular projects } \\
\text { (exchange, correspondence, etc.). }\end{array}$ \\
\hline
\end{tabular}

\section{APPEndix III. IDENTIFICATION AND IMPROVEMENT PRIORITISATION OF PROCESSES}

Example

\begin{tabular}{|l|l|l|l|l|c|c|}
\hline PROCESS & $\begin{array}{c}\text { GENERAL } \\
\text { DESCRIPTION } \\
\text { OF PRESENT } \\
\text { FUNCTIONING } \\
\text { OF PROCESS }\end{array}$ & $\begin{array}{l}\text { GOOD POINTS AND AREAS } \\
\text { OF IMPROVEMENT }\end{array}$ & $\begin{array}{l}\text { VIABILITY } \\
\text { 1. Low } \\
\text { 2. Medium } \\
\text { 3. High }\end{array}$ & $\begin{array}{l}\text { PRIORITY } \\
\text { 1. Low } \\
\text { 2. Medium } \\
\text { 3. High }\end{array}$ & $\begin{array}{l}\text { Own } \\
\text { score }\end{array}$ & $\begin{array}{c}\text { Group } \\
\text { score }\end{array}$ \\
\hline $\begin{array}{l}\text { Correction } \\
\text { of } \\
\text { workbook }\end{array}$ & $\begin{array}{l}\text { All students are } \\
\text { required to } \\
\text { complete } \\
\text { workbook. } \\
\text { Workbook is } \\
\text { collected at end of } \\
\text { each term and } \\
\text { browsed over'. }\end{array}$ & $\begin{array}{l}\text { Good points: } \\
\text { All pupils have workbook and } \\
\text { Aost exercises are appropriate. } \\
\text { Areas of improvement: } \\
\text { - - Many too pong to correct all } \\
\text { - Not all exercises are } \\
\text { appropriate for all students }\end{array}$ & 2 & 3 & 5 & 20 \\
\hline & & & & & & \\
\hline & & & & & & \\
\hline
\end{tabular}


APPEndix IV. Suggested STRATEgy IMPLEMENTAtion PROCESS

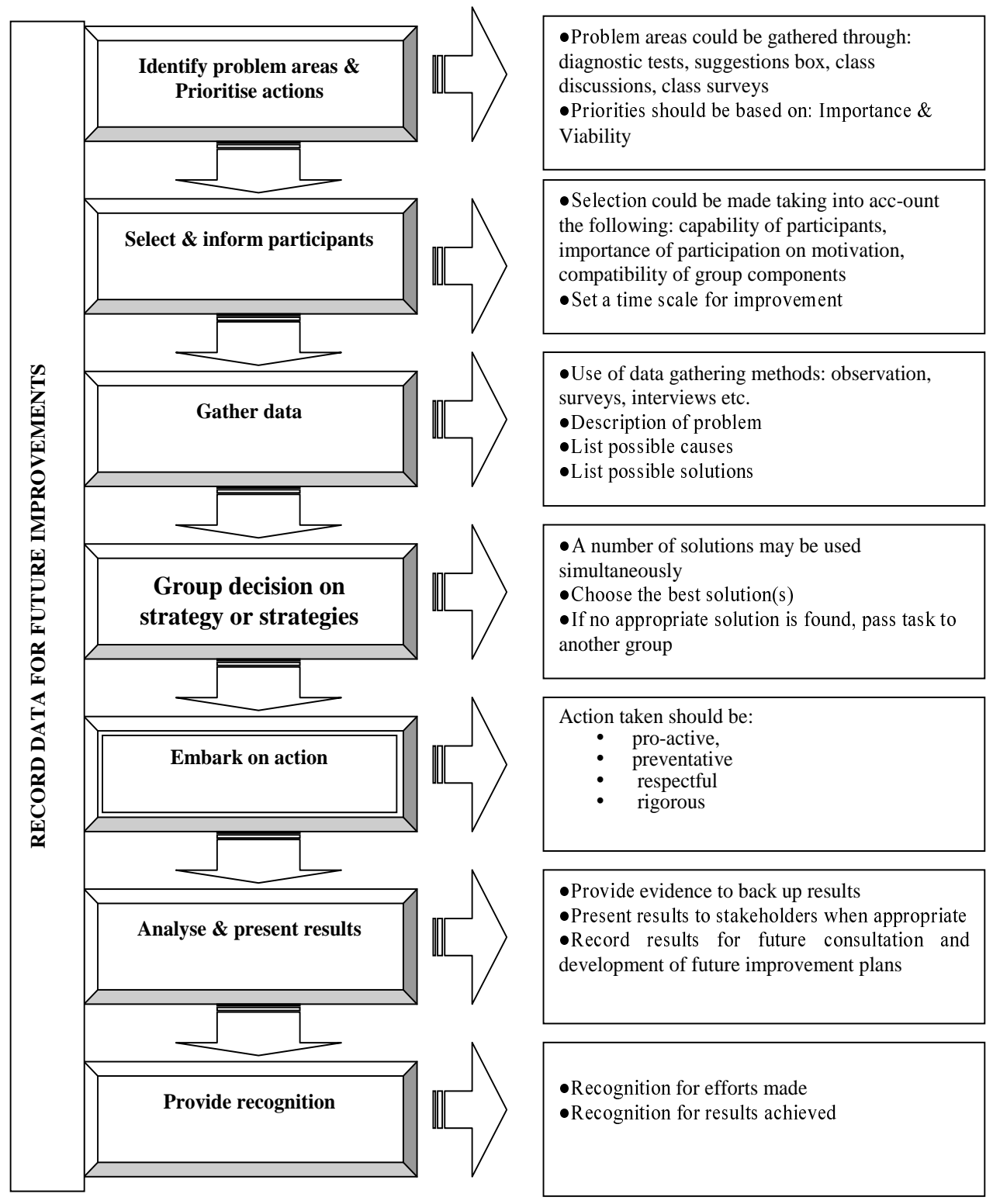

